\title{
Brandrodung oder prähistorischer Waldbrand?
}

Am 4. Oktober 1971 führte mich ein denkmalpflegerisches Anliegen nach Camplun im hintersten Lugnez (Gemeinde Vrin, LK 1:25'000 Blatt 1234). Damals war gerade das neue landwirtschaftliche Fahrsträsschen von $\mathrm{S}_{\text {。 Giusep }}$ nach Puzzatsch im Bau. Die Stufe zwischen den Verflachungen von Chischnè (Hof unmittelbar oberhalb S. Giusep) und Camplun wurde dabei mit einer neuen Linienführung überwunden (Abb。1)。In der Abgrabung, welche das an den Hang angelehnte Trassee nötig machte, entdeckte meine Frau einen aufälligen dunklen Horizont, der sich beim näheren Hinsehen als durchlaufende Schicht reiner Holzkohle erwies, in der auch einzelne verkohlte Holzteile eindeutig feststellbar waren.

$\mathrm{Da}$ ich bei den Arbeiten für meine Dissertation ${ }^{1}$ darauf gestossen war, dass der Wald zwischen Cons und Puzzatsch möglicherweise 1593 durch einen Brand vernichtet worden war, beschloss ich, eine Probe zur Datierung zu nehmen。Situation des Kohlehorizontes und Entnahmestelle sind aus den Abb。2 - 4 ersichtlich. Güucklicherweise hatte ich Gelegenheit, eine ${ }^{4} \mathrm{C}$ - Datierung vornehmen zu lassen. Dem Geographischen Institut der Universität Zürich und Herrn Prof。 G。 Furrer sei dafür gedankt. Die Datierung wurde in Lyon vorgenommen. Das Ergebnis bedeutete nun aber keineswegs eine Bestätigung für den Waldbrand von 1593, sondern ein archäologisches Problem. Dąs Alter der Probe wurde nämlich auf $2480-110$ BP bestimmt, der Kohlehorizont müsste demnach in der Zeit zwischen 640 und 420 v. u. $Z$. entstanden sein. Es wird also Sache des archäologischen Dienstes des Kantons Graubünden sein, die Bedeutung des Fundes abzuklären.

Hier seien nur noch einige Gedanken über die geographischen Aspekte angefügto Die Fundstelle liegt in einem Uebergangsgebiet zwischen dem süd- und dem inneralpinen Raum, das im Mittelalter eine grosse lokale Bedeutung hatte, in prähistorischer Zeit aber möglicherweise sogar eine überregionale. Aus der Epoche der römischen Beherrschung Rätiens fehlen allerdings bisher Hinweise für die Begehung der Diesrut-Greina-Route und der Nebenverbindung über die Fuorcla dil Terri und Crap la Crusch.

Hingegen ist die Lage der berühmten bronzezeitlichen Höhensiedlung Crestaulta bei Surin (Gemeinde Lumbrein) sicher mit einer grossen verkehrsmässigen Bedeutung des Gebietes in Zusammenhang zu bringen. (Hier dürfte übri- gens auch der Hügel Pt. 1512 südlich von Plaun Tgiern, gegenüber Cons in der Gemeinde Vrin, eine gewisse Aufmerksamkeit verdienen。)

Der fragliche Kohlehorizont siteht allerdings kaum in direktem Zusammenhang mit den Siedlungen auf Crestaulta, liegen doch die dort festgestellten Siedlungsepochen zwischen 1700 und 1100 vou. Z.2)。 Hingegen hat eine andere Fundstelle im Lugnez, nämlich Surcasti (Qherkastels) eisenzeitliches Material geliefert 3$)^{3}$ $\mathrm{Da}$ von der fraglichen Fundstelle bis jetzt noch keine Artefakte vorliegen, ist ein kultureller Zusammenhang mit Surcasti weder erwiesen noch auszuschliessen; die Bedeutung des Fundes ist noch völlig offen und es müssen meh) rere Möglichkeiten in Betracht gezogen werden. Ob Hinweise für die kulturelle Einordnung gefunden werden, ist überdies nicht sicher, wenn es sich beispielsweise lediglich um die Ueberreste einer Brandrodung handelt. Schliesslich könnte die Kohle auch ohne menschliches Zutun durch einen spontan - zum Beispiel durch Blitzschlag - entstandenen Waldbrand gebildet worden sein。

Auf jeden Fall kann man auf die Ergebnisse einer genaueren Untersuchung durch die Fachleute gespannt sein, welche Erklärung sich für die Entstehung des Kohlehorizontes auch immer ergibt。

\section{Anmerkungen:}

Oberlugnez, Wirtschafts- und SiedlungsEntwicklung vom Ende des Mittelalters bis zum 20. Jahrhundert, Zürich 1972。

Burkart, Walo; Crestaulta, eine bronzezeitliche Hügelsiedlung bei Surin im Lugnez, Basel 1946

3)

Mitteilung von Herrn Dr。Zindel, Archäologischer Dienst Graubünden

Dr. Walter Büchi, Blumenstraße 15,8152 Glattbrugg 
Abb. 1 Die neue Linienführung zwischen den Verflachungen von Chischnè und Camplun.

Abb. 2-4 Situation des Kohlehorizontes und Probeentnahmestelle.
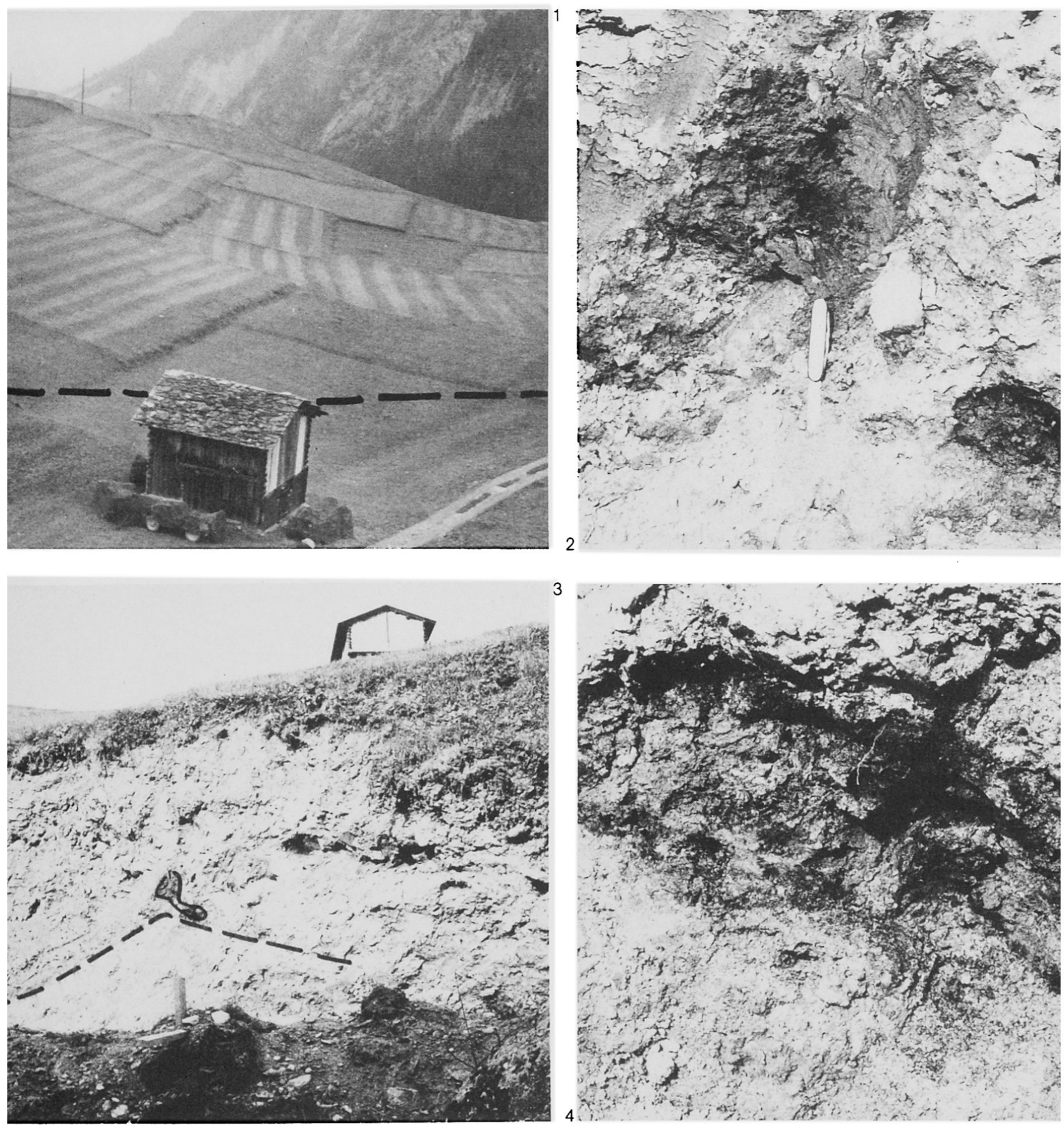